\title{
Validation of the Model of End-Stage Liver Disease for Liver Transplant Allocation in Alberta: Implications for Future Directions in Canada
}

\author{
Kelly W. Burak, ${ }^{1}$ Glenda A. Meeberg, ${ }^{2}$ Robert P. Myers, ${ }^{1}$ Gordon H. Fick, ${ }^{3}$ Mark G. Swain, ${ }^{1}$ \\ Vincent G. Bain, ${ }^{2}$ Norman M. Kneteman, ${ }^{2}$ and Robert J. Hilsden ${ }^{3}$ \\ ${ }^{1}$ Liver Unit, Division of Gastroenterology and Hepatology, Department of Medicine, University of Calgary, Calgary, \\ AB, Canada T2N $4 Z 6$ \\ ${ }^{2}$ Alberta Liver Transplant Program, University of Alberta, Edmonton, AB, Canada \\ ${ }^{3}$ Department of Community Health Sciences, University of Calgary, Calgary, AB, Canada
}

Correspondence should be addressed to Kelly W. Burak; kwburak@ucalgary.ca

Received 10 February 2015; Accepted 27 April 2015

Copyright (C) 2016 Kelly W. Burak et al. This is an open access article distributed under the Creative Commons Attribution License, which permits unrestricted use, distribution, and reproduction in any medium, provided the original work is properly cited.

\begin{abstract}
Background. Since 2002, the Model of End-Stage Liver Disease (MELD) has been used for allocation of liver transplants (LT) in the USA. In Canada, livers were allocated by the CanWAIT algorithm. The aim of this study was to compare the abilities of MELD, Child-Pugh (CP), and CanWAIT status to predict 3-month and 1-year mortality before LT in Canadian patients and to describe the use of MELD in Canada. Methods. Validation of MELD was performed in 320 patients listed for LT in Alberta (1998-2002). In October 2014, a survey of MELD use by Canadian LT centers was conducted. Results. Within 1 year of listing, 47 patients were removed from the waiting list (29 deaths, 18 too ill for LT). Using logistic regression, the MELD and CP were better than the CanWAIT at predicting 3-month (AUROC: $0.79,0.78$, and 0.59; $p=0.0002$ ) and 1-year waitlist mortality (AUROC: $0.70,0.70$, and $0.55 ; p=0.0023$ ). Beginning in 2004, MELD began to be adopted by Canadian LT programs but its use was not standardized. Conclusions. Compared with the CanWAIT system, the MELD score was significantly better at predicting LT waitlist mortality. MELD-sodium (MELD-Na) has now been adopted for LT allocation in Canada.
\end{abstract}

\section{Introduction}

Liver transplant (LT) is often the only life-extending option for patients with acute liver failure (ALF) and complications of chronic liver disease. In recent years, the demand for LT has dramatically increased, largely due to the burden of chronic hepatitis C virus (HCV) in Canada [1]. However, wait times for LT have significantly lengthened because the supply of cadaveric and live donor organs has not increased enough to meet this demand. In Alberta, we saw a fourfold increase in mean waiting time for adult cadaveric LT between 2000 and 2004 alone (Figure 1).

In 1998, the United Network of Organ Sharing (UNOS) adopted minimal listing criteria in the United States for patients to be placed on the LT waiting list [2]. ChildPugh (CP) classification (Table 1) was used to place patients with chronic liver disease into three categories of disease severity. With many patients in each category, ties were then broken by length of time on the waiting list. In 2000, the US Department of Health and Human Services mandated the emphasis on waiting time be removed from the process of organ allocation [3]. UNOS adopted the Model of EndStage Liver Disease (MELD) score in February 2002 as an objective means of allocating organs to the patients with the greatest need [3]. The MELD score (based on bilirubin, creatinine, and INR) was first used to predict survival after transjugular portosystemic intrahepatic shunting [4] and was later validated as a predictor of mortality in patients awaiting LT in the USA and Europe [5-8]. The MELD policy has resulted in fewer patients being listed for LT and fewer deaths on the waitlist without changing mortality rates following LT in the USA $[9,10]$. The organ allocation system in Canada is based on the CanWAIT algorithm (Table 2), which ranks patients according to location (intensive care unit, hospital 
TABle 1: Child Pugh (CP) classification.

\begin{tabular}{lccc}
\hline Variable & 1 point & 2 points & 3 points \\
\hline Ascites & None & Easily controlled & Poorly controlled \\
Encephalopathy & None & Grade 1 or 2 & Grade 3 or 4 \\
Albumin $(\mathrm{g} / \mathrm{L})$ & $<35$ & $28-35$ & $<28$ \\
Bilirubin $(\mu \mathrm{mol} / \mathrm{L})$ & $<34$ & $34-51$ & $>51$ \\
INR & $<1.7$ & $1.7-2.3$ & $>2.3$ \\
\hline
\end{tabular}

Abbreviation: INR, international normalized ration of prothrombin time.

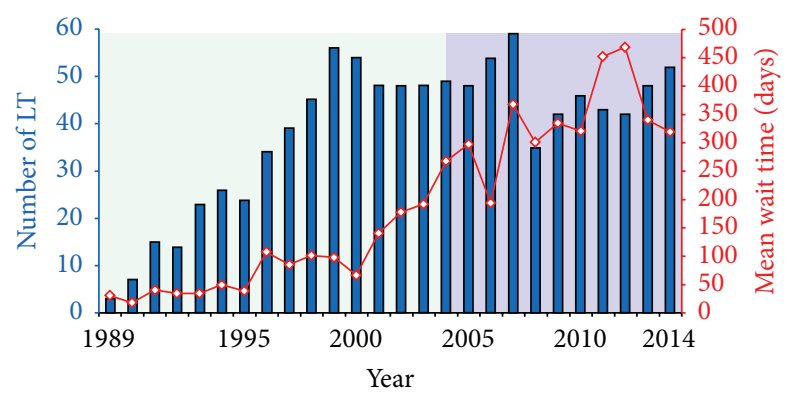

Figure 1: Number of adult cadaveric liver transplants performed per year (bars) and the mean waiting time in days (lines) for liver transplant in Alberta (1989-2014).

ward, or home), and similar to the previous $\mathrm{CP}$ based system in the USA, it relies heavily upon waiting time to break ties within categories. Therefore, the primary purpose of this research was to validate the ability of the MELD score to predict mortality in a cohort of Canadian patients and to determine if MELD was superior to the CP score and CanWAIT status in predicting waitlist mortality.

In October 2005, the first annual Canadian Liver Transplant Forum (CLTF) was held in Montreal to address the question: Should Canada adopt MELD for LT allocation? Starting with Alberta in July 2004, LT programs in Canada began to adopt MELD for LT allocation locally for nonurgent status patients. However, MELD use in Canada has not been standardized and therefore the CLTF-9 meeting held in Montreal in October 2014 was once again focused on advancing consensus around listing criteria for LT in Canada.

\section{Methods}

We examined a historical cohort of patients at the University of Alberta, from whom data had been collected prospectively into a database. Adult patients ( $>18$ years old) who were listed for cadaveric LT between January 1, 1998, and December 31, 2002, were included in the study. Exclusion criteria included pediatric patients $(<18$ years old), previous solid organ transplants (including liver), simultaneous small bowel or renal transplants, live donor liver transplants (LDLT), patients who voluntarily removed themselves from the list, patients who recovered liver function (too well to need LT), patients who were delisted for active substance abuse or medical issues discovered prior to activation, and patients without complete laboratory data to calculate the MELD within 3 months of the
TABLE 2: CanWAIT allocation system.

\begin{tabular}{ll}
\hline CanWAIT & Definition \\
\hline $4 \mathrm{~F}$ & ALF in ICU on ventilator \\
4 & Chronic liver disease in ICU on ventilator \\
$3 \mathrm{~F}$ & ALF in ICU not requiring mechanical ventilation \\
\hline 3 & $\begin{array}{l}\text { Chronic liver disease in ICU for Grade } 3 \text { or } 4 \\
\text { encephalopathy or renal dysfunction but not } \\
\text { requiring ventilation }\end{array}$ \\
2 & $\begin{array}{l}\text { Chronic liver disease in hospital } \\
1 \mathrm{~T}\end{array}$ \\
1 & Chronic liver disease at home with HCC \\
0 & Chronic liver disease at home \\
\hline
\end{tabular}

Note: Organs were shared nationally for urgent status (3F, 4, 4F) until May 2010 after which national sharing was restricted to patients with acute liver failure only (3F, $4 \mathrm{~F})$.

Abbreviations: ALF, acute liver failure; ICU, intensive care unit; HCC, hepatocellular carcinoma.

listing date for LT (Figure 2). This study did include patients who were listed with fulminant acute liver failure (ALF = status $3 \mathrm{~F}$ or $4 \mathrm{~F}$ ), although these patients receive preferential status and in the USA are not ranked by the MELD score. Also some of the hepatocellular carcinoma (HCC) patients were given preferential status (status 1T) beginning in 2001. Therefore, separate analysis was performed both including and excluding ALF and HCC patients.

The MELD score was calculated as per the original model [4] without the disease category:

$$
\begin{aligned}
& \text { [0.957 } \ln (\text { creatinine })+0.378 \ln \text { (bilirubin }) \\
& +1.12 \ln (\mathrm{INR})+0.643] \times 10 .
\end{aligned}
$$

Creatinine and bilirubin were converted from $\mu \mathrm{mol} / \mathrm{L}$ to $\mathrm{mg} / \mathrm{dL}$ (conversion factors 17.1 for bilirubin and 88.4 for creatinine). The MELD score was calculated as per UNOS guidelines, with the following exceptions: no extra points were awarded for HCC, and the score was not capped at 40.

The primary outcome variable in this study was mortality defined as death or delisting for being too ill. Logistic regression was used to examine the ability of MELD, CP, and CanWAIT status to predict 3-month and 1-year mortality on the LT waitlist. The models were compared using a chisquared test for the equality of the area under the receiver operating characteristic (AUROC) curves [11]. The AUROC curve has become the most frequently performed statistical analysis in the validation studies of the MELD score [5-8]. The AUROC curve ranges from 0 to 1 , with 1 representing perfect discrimination and 0.5 being due to chance alone. A diagnostic or prognostic test is generally accepted as clinically useful when the AUROC is $\geq 0.7$ and AUROC of $0.8-0.9$ indicates an excellent ability to predict an outcome. The ability of the MELD score to predict one-year waitlist survival was also examined using standard survival analysis techniques. Kaplan-Meier curves were compared using the log rank test. Hazard ratios were calculated using Cox proportional hazards models and formal testing was done to 


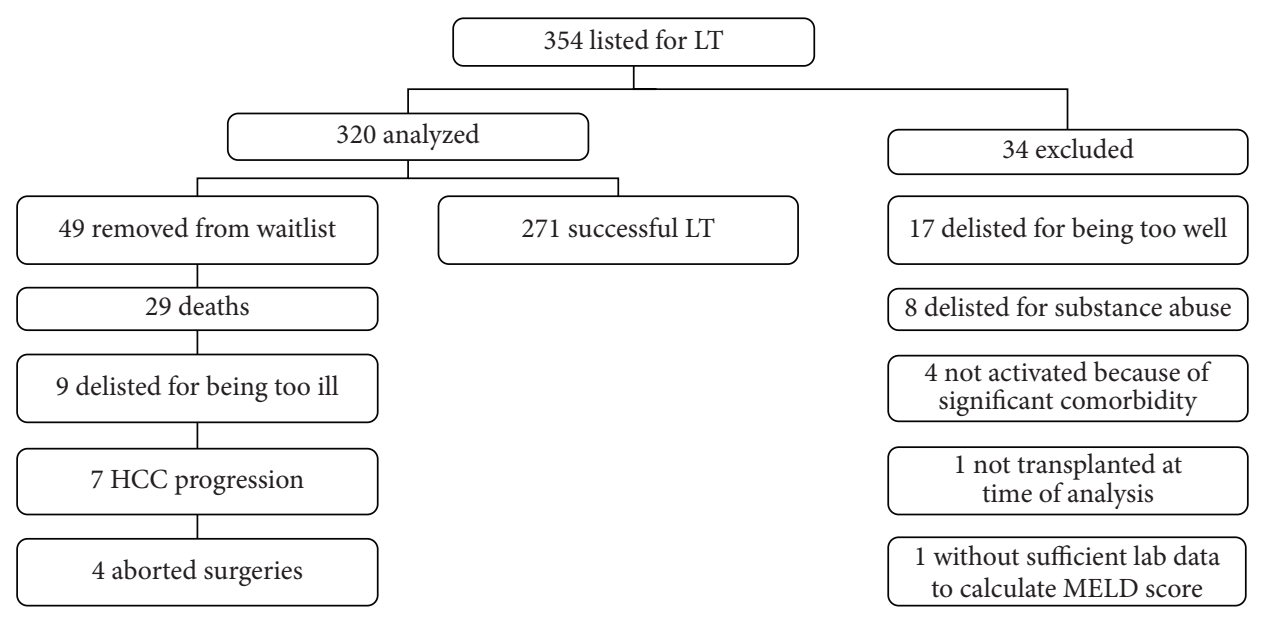

Figure 2: Flow chart of study subjects.

confirm that the assumption of proportional hazards was not violated. All statistical tests were performed using STATA 8.0 software. Tests of significance were two-sided with an alpha value of 0.05 . Prior to initiating this project the Research Ethics Boards (REB) at the University of Calgary and the University of Alberta reviewed and approved this protocol.

In October 2014, a survey was conducted of all adult LT programs in Canada asking five questions:

(1) When did you officially start allocating organs according to the MELD?

(2) Do you still respect the CanWAIT status over MELD (does a hospitalized patient with a lower MELD score get an organ before a patient at home with a higher MELD score)?

(3) What version of MELD do you currently use (MELD/ MELD-Na/other)?

(4) Describe how do you give MELD exemption points for HCC?

(5) What other diagnoses regularly receive MELD exemption points in your centre?

These results were tabulated and presented at the CLTF-9 meeting in Montreal on October 18, 2014.

\section{Results}

3.1. MELD Validation. A total of 354 adults met inclusion criteria and were listed for LT in Alberta during the study period. Thirty-four subjects were excluded, leaving 320 patients for analysis (Figure 2 ). The mean age $( \pm \mathrm{SD})$ of subjects listed was $50.2 \pm 10.0$ years and more males were listed than females (67.5\% versus $32.5 \%)$. The most common indications for LT were alcoholic liver disease (33.4\%) and HCV (32.8\%) and only 15 subjects (4.7\%) had ALF.

Table 3 shows the CanWAIT status at the time of listing. Nearly one-third of patients were listed as status 0 (pending further investigations before being activated). The status 0 group included patients who were later transplanted as status
TABLE 3: The distribution of patients and overall mortality rates within MELD strata, CP classes and CanWAIT.

(a)

\begin{tabular}{lcccc}
\hline MELD & $N$ & \% Total & Deaths & \% Mortality \\
\hline$<10$ & 92 & $28.8 \%$ & 7 & $7.6 \%$ \\
$10-19$ & 160 & $50 \%$ & 22 & $13.8 \%$ \\
$20-29$ & 46 & $14.4 \%$ & 11 & $23.9 \%$ \\
$30-39$ & 15 & $4.7 \%$ & 7 & $46.7 \%$ \\
$\geq 40$ & 7 & $2.2 \%$ & 2 & $28.6 \%$ \\
\hline
\end{tabular}

(b)

\begin{tabular}{lcccc}
\hline CP class & $N$ & \% Total & Deaths & \% Mortality \\
\hline A (5-6) & 32 & $10 \%$ & 3 & $9.4 \%$ \\
B (7-9) & 145 & $45.3 \%$ & 10 & $6.9 \%$ \\
C (10-15) & 143 & $44.7 \%$ & 36 & $25.2 \%$ \\
\hline
\end{tabular}

(c)

\begin{tabular}{lcccc}
\hline CanWAIT status & $N$ & \% Total & Deaths & \% Mortality \\
\hline 0 & 105 & $32.8 \%$ & 15 & $14.3 \%$ \\
1 & 146 & $45.6 \%$ & 20 & $13.7 \%$ \\
$1 \mathrm{~T}$ & 9 & $2.8 \%$ & 2 & $22.2 \%$ \\
2 & 43 & $13.4 \%$ & 7 & $16.3 \%$ \\
3 & 4 & $1.3 \%$ & 1 & $25 \%$ \\
$3 \mathrm{~F}$ & 1 & $0.3 \%$ & 0 & $0 \%$ \\
4 & 4 & $1.3 \%$ & 2 & $50 \%$ \\
$4 \mathrm{~F}$ & 8 & $2.5 \%$ & 2 & $25 \%$ \\
\hline
\end{tabular}

$1(n=57)$, status $1 \mathrm{~T}(n=4)$, status $2(n=22)$, status $4(n=6)$, and status $4 \mathrm{~F}(n=1)$. The median MELD score was 14 (range 5 to 49$)$. Of the 320 subjects, 271 patients (84.7\%) successfully underwent LT. A total of 49 patients (15.3\%) were removed from the waitlist because of death or delisting for being too ill (Figure 2). Thirty-one removals occurred within 3 months of listing and 47 of the 49 removals occurred within one year of listing. The mortality rates on the waitlist by MELD strata, 


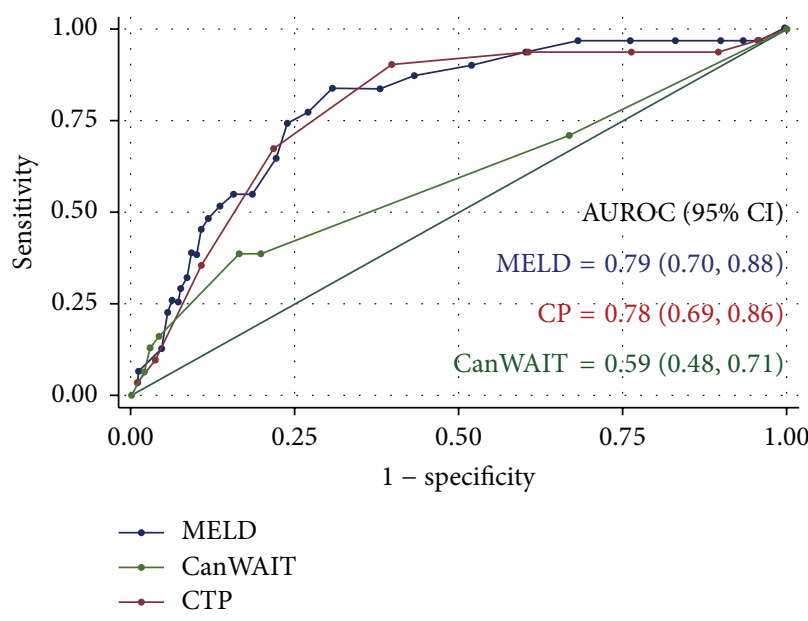

(a)

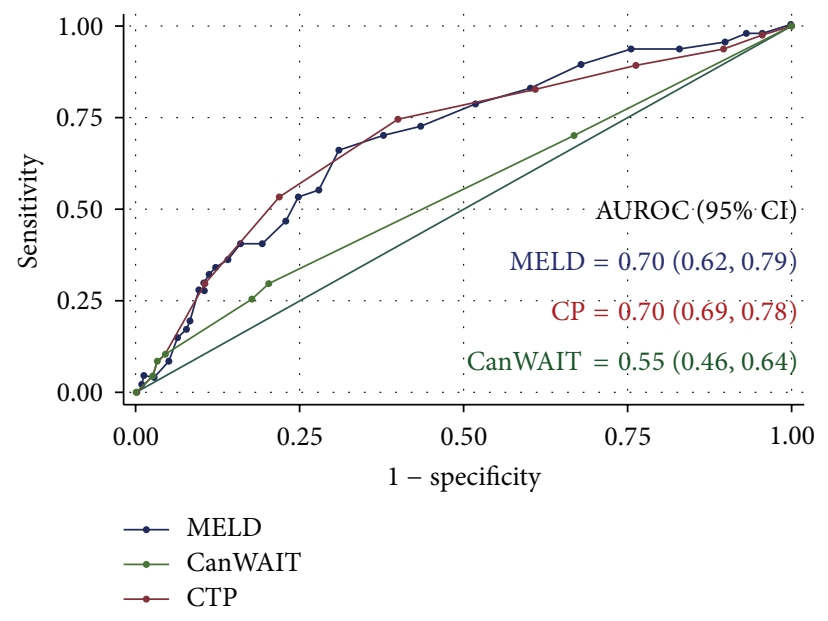

(b)

FIGURE 3: Receiver operating characteristic (ROC) curves for MELD, CP, and CanWAIT scores for prediction of 3-month (a) and 1-year (b) waiting list mortality.

$\mathrm{CP}$ class, and CanWAIT categories are shown in Table 3. The mortality rates ranged from $7.6 \%$ for MELD scores $\leq 9$ to $46.7 \%$ for MELD scores between 30 and 39. Within the CP classes, the highest mortality rates $(25.2 \%)$ were seen in $\mathrm{CP}$ class $C$. Although the numbers were very small, patients with chronic liver disease on a ventilator (status 4 ) had the highest mortality rate within the CanWAIT system.

The median MELD score in subjects who died within the first 3 months of listing was 21 (range 10 to 45 ) compared to a median MELD score of 15 (range 6 to 44) for those surviving (Mann-Whitney test, $p=0.018$ ). The median MELD score in subjects who died within the first year of listing was 19 (range 6 to 43) compared to a median MELD score of 14 (range 5 to $49)$ for those surviving $(p<0.0005)$. The ROC curves for 3 month and 1-year waiting list mortality are shown in Figure 3. For the prediction of 3-month mortality the AUROC curves were similar for the MELD and CP scores $(p=0.70)$. The AUROC for the CanWAIT status was only 0.59 and was significantly lower than the AUROC curve for both the $\operatorname{MELD}(p=0.0002)$ and CP $(p=0.0015)$ scores. For the prediction of 1-year waiting list mortality the AUROC curve was similar for the MELD and CP scores $(p=0.93)$. For the CanWAIT status it was only 0.55 and was significantly lower than the AUROC curve for both MELD $(p=0.0023)$ and $\mathrm{CP}(p=0.006)$ scores. The ROC curves after excluding ALF and status $1 \mathrm{~T}$ patients $(n=292)$ were nearly identical to the previous analysis (data not shown).

The survival curves for the different MELD strata are shown in Figure 4 . The log rank test for equality of survivor functions between different MELD categories was significant $(p<0.0005)$. Using the MELD $<10$ strata as the comparison group, only MELD strata $\geq 20$ had significant hazard ratios for mortality at 1 year (Table 4).

3.2. MELD Use in Canada. LT allocation policy in Canada primarily focuses on sharing of organs for urgent status patients, which until May 2010 included statuses 3F, 4,
TABLE 4: Cox proportional hazards models for 1-year wait list mortality for different MELD strata.

\begin{tabular}{lcccc}
\hline MELD & $N$ & HR & $(95 \%$ CI $)$ & $p$ value \\
\hline$<10$ & 92 & - & - & - \\
$10-19$ & 160 & 1.74 & $(0.74,4.12)$ & 0.207 \\
$20-29$ & 46 & 8.48 & $(3.17,22.64)$ & $<0.0005$ \\
$30-39$ & 15 & 82.02 & $(24.28,277.08)$ & $<0.0005$ \\
$\geq 40$ & 7 & 54.88 & $(10.35,290.95)$ & $<0.0005$ \\
\hline
\end{tabular}

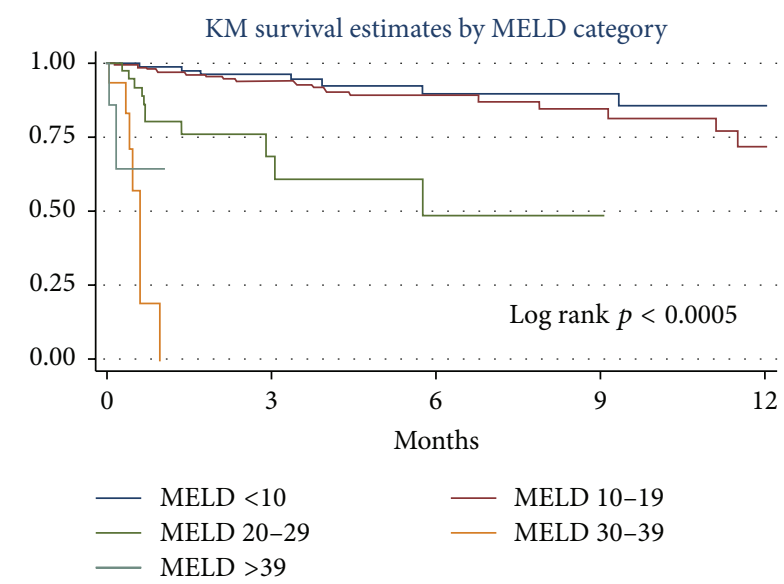

FIgURE 4: Kaplan-Meier survival estimates of 1-year waiting list survival for different strata of MELD scores.

and $4 \mathrm{~F}$, after which interprovincial sharing was restricted to only acute liver failure patients (statuses $3 \mathrm{~F}$ and $4 \mathrm{~F}$ ). Center-specific variation for allocation of organs to nonurgent patients therefore exists. MELD began to be adopted in other jurisdictions in Canada starting in 2004 (Table 5); however, only British Columbia would take into account the patient's status (hospitalized versus home) when deciding 
TABLE 5: Survey of MELD use in Canada (October 2014).

\begin{tabular}{|c|c|c|c|c|c|}
\hline & $\mathrm{BC}$ & $\mathrm{AB}$ & $\mathrm{ON}$ & PQ & ATL \\
\hline System & $\begin{array}{l}\text { MELD and } \\
\text { CanWAIT }\end{array}$ & $\begin{array}{l}\text { MELD } 20^{*} \text { and } \\
\text { CanWAIT }\end{array}$ & MELD $\rightarrow$ MELD-Na & MELD-Na & $\begin{array}{l}\text { MELD } \rightarrow \text { Refit } \\
\text { MELD-Na }\end{array}$ \\
\hline Adopted & 2006 & JUL 2004 & $2006 \rightarrow$ NOV 2012 & JUL 2008 & $2006 \rightarrow 2012$ \\
\hline Criteria for HCC & $\begin{array}{l}\text { Milan } \\
\text { (UCSF) }\end{array}$ & TTV115 + AFP400 & $\begin{array}{c}\text { TTV115 + AFP } 400 \\
\text { or UCSF }\end{array}$ & Milan & $\begin{array}{c}\text { Milan } \\
\text { (UCSF) }\end{array}$ \\
\hline HCC Exemptions & $\begin{array}{l}\text { MELD } 15 \\
+10 \% \mathrm{q} 3 \mathrm{~m}\end{array}$ & $\begin{array}{l}\text { MELD } 22 \\
+2 \text { pts q3m }\end{array}$ & $\begin{array}{l}\text { MELD-Na } 22 \\
+3 \text { pts q3m }\end{array}$ & $\begin{array}{c}\text { PQ-HCC-MELD } \\
\text { q3m }\end{array}$ & Refit MELD-Na 22 \\
\hline Other Exemptions & None & $\begin{array}{c}\text { HPS, PPHT, } \\
\text { Cholangitis, and } \\
\text { others }\end{array}$ & $\begin{array}{l}\mathrm{HPS}, \mathrm{FAP}, \mathrm{HB}, 1^{\circ} \mathrm{HO} \text {, } \\
\mathrm{CF}, \text { metabolic, CCA, } \\
\text { Failed LDLT or DCD }\end{array}$ & $\begin{array}{l}\text { Cholangitis, HE, HPS, } \\
\text { HEHE, and others }\end{array}$ & $\begin{array}{l}\text { Cholangitis, PCLKD, } \\
\text { and others }\end{array}$ \\
\hline
\end{tabular}

Abbreviations: BC, British Columbia; AB, Alberta; ON, Ontario; PQ, Quebec; ATL, Atlantic Canada; MELD, model of end-stage liver disease; MELD-Na, MELD-sodium; UCSF, University of California San Francisco; TTV115, total tumour volume $\leq 115 \mathrm{~cm}^{3}$; AFP400, alpha-fetoprotein $\leq 400 \mathrm{ng} / \mathrm{mL}$; q3m, every three months; HPS, hepatopulmonary syndrome; PPHT, porto-pulmonary hypertension; FAP, familial amyloidosis polyneuropathy; $1^{\circ} \mathrm{HO}$, primary hyperoxyluria; CF, cystic fibrosis; CCA, cholangiocarcinoma; LDLT, live donor liver transplantation; HE, hepatic encephalopathy; HEHE, hepatic epitheliod hemangioendothelioma; PCLKD, polycystic liver and kidney disease.

${ }^{*}$ MELD 20 policy (July 2004-December 2014) = Patients waiting at home (status 1) with a MELD $\geq 20$ were given priority; however, hospitalized patients (status 2) with a lower MELD score would still receive an organ first.

who is next to receive a nonurgent transplant. As seen in Table 5, many provinces in Canada have more recently adopted variations of the MELD score to allocate organs, and across the country there exists significant variability in selection criteria for HCC patients and how exemptions are handled for tumour patients and other indications.

\section{Discussion}

In our validation study, the MELD score was significantly better at predicting waitlist mortality than the CanWAIT system. The AUROC for 3-month mortality approached 0.80 indicating that it is a good prognostic test for predicting short-term mortality on our LT waitlist. The AUROC curve for the MELD score was similar to other validation studies, in which AUROC curve ranged from 0.78 to 0.87 for the prediction of 3-month mortality [5-8]. In contrast, the AUROC curve for the CanWAIT algorithm was no better than chance alone at predicting waiting list mortality (95\% CI included 0.5). The ability of the MELD score to predict longer-term mortality in Alberta was diminished, but the AUROC curve of 0.7 indicates that the MELD is still a useful model for predicting 1-year waitlist mortality. The inclusion or exclusion of ALF patients did not dramatically change the AUROC curves, and although not used for allocation in this patient population, there is evidence that the MELD score is a useful predictor of survival in patients with ALF [12].

Limitations of our study include its retrospective nature and the relatively small sample size of this single center experience. There were only small numbers of patients listed in the higher CanWAIT status categories. Another limitation was the inclusion of status 0 patients in the analysis. Although status 0 patients cannot receive a LT until they are activated, it was important to include these potential LT recipients to capture all wait time and all patients who died or were delisted for being too ill (15 out of 49 removals from the list were in status 0 patients).
Since MELD was adopted for LT allocation in the USA, many groups have examined if improvements can be made in the predictive capabilities of the model by refitting the coefficients of the existing variables or adding new variables to the model. Hyponatremia is an independent predictor of mortality in cirrhotics, and it has been suggested that addition of sodium to the model (MELD-Na) could potentially prevent $7 \%$ of waitlist deaths [13]. The MELD-Na has been adopted by the four adult LT programs in Ontario and Quebec. The MELD and MELD-Na have been refit to better predict mortality in patients awaiting LT [14]. Halifax has been using the refit MELD-Na for allocation since 2012. The predictive models for LT waitlist mortality have recently been reviewed by the Scientific Registry of Transplant Recipients (SRTR), and it appears that MELD$\mathrm{Na}$ (with updated coefficients) is the best model for organ allocation (personal communication from Dr. Ray Kim). UNOS will be moving to adopt MELD-Na for LT allocation in the USA in the near future, and at the CLTF-9 meeting the Canadian LT Network voted to endorse MELD-Na (with the SRTR coefficients) as the universal allocation system for adult LT in Canada beginning on January 1, 2015. Therefore, the CanWAIT system now ceases to exist, although data on the location of the patient at the time of transplant (home, hospital, or ICU) will continue to be tracked.

In October 2005, Canadian LT hepatologists and surgeons met at the first CLTF in Montreal to discuss one fundamental question: Should Canada adopt the MELD as a means of organ allocation? Our validation study, which confirmed the ability of the MELD scoring system to predict short-term waiting list mortality in a cohort of Canadian patients, was presented at that meeting. As MELD was shown to be superior to the current CanWAIT system in predicting death while awaiting LT, there was universal support for adopting MELD for LT allocation in Canada. However, without an equivalent agency to UNOS in Canada, things 


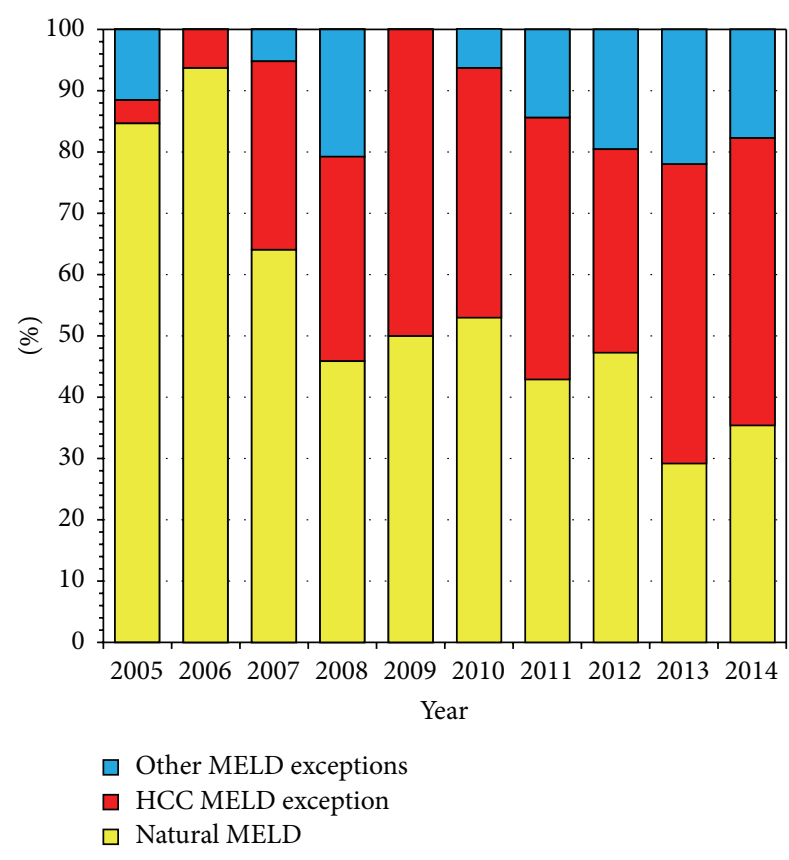

FIgURE 5: Percentage of adult LT in Alberta transplanted according to natural MELD versus exception points for HCC or other indications since adopting MELD based allocation.

have moved slowly, and as our 2014 survey indicates, MELD has been adopted in various forms across the country over the subsequent years.

Furthermore, there remains considerable variability in listing practices for HCC and how MELD exemptions are handled. BC and Atlantic Canada transplant HCC patients who are mainly within the Milan criteria (single $\mathrm{HCC} \leq 5 \mathrm{~cm}$ or up to three $\mathrm{HCC}$ each $\leq 3 \mathrm{~cm}$ ), although they will consider tumours within the UCSF criteria (single $\mathrm{HCC}<6.5 \mathrm{~cm}$ or up to three $\mathrm{HCC}$, none that are $>4.5 \mathrm{~cm}$, and cumulative tumour size $<8 \mathrm{~cm}$ ), on a case-by-case basis. In Alberta, since 2007, we have been transplanting HCC patients using a total tumour volume (TTV) of $\leq 115 \mathrm{~cm}^{3}$ and alpha-fetoprotein $(\mathrm{AFP}) \leq 400 \mathrm{ng} / \mathrm{mL}$ as selection criteria $[15,16]$. These criteria were subsequently adopted by the London program and then Ontario as a provincial policy in 2012, although patients can still be transplanted within UCSF criteria as well. In Quebec, they have a unique method of delivering MELD$\mathrm{Na}$ exception points to some HCC patients, with this being assessed every three months [17]. How HCC patients are moved up the waitlist with exemption points is also not standardized in Canada (Table 5). However, after reviewing the prospective validation of TTV115 + AFP400 criteria at the CLTF-8 meeting (October 26, 2013, in Montreal) there was consensus to move forward with adopting this as a universal listing criterion for HCC in Canada.

A look at our adult patients in Alberta since we moved to MELD based allocation indicates that the majority of our patients are currently transplanted with MELD exception points, either for HCC or for other indications such as recurrent cholangitis, hepatopulmonary syndrome, or portopulmonary hypertension (Figure 5). Canadian Blood Services (CBS) is currently planning a LT Consensus Workshop in early 2016 to move forward the process of standardizing LT allocation policy, listing criteria, and how to handle MELD-Na exemptions in Canada. This will be extremely important if we wish to have universal and equitable access to LT in our country.

In conclusion, MELD is superior to the CanWAIT system for predicting waitlist mortality and has been validated in Canadian cohort of patients awaiting LT. Several modifications of MELD have subsequently been developed, and starting in January 2015, Canada has adopted MELD-Na (with SRTR coefficients) for LT allocation. There remains considerable heterogeneity in listing criteria and how MELD exceptions are handled in Canada and further consensus building workshops, along with a functional data management system, will be required to move this process forward.

\section{Competing Interests}

The authors declare that they have no competing interests.

\section{Acknowledgments}

This work was completed as part of an M.S. degree in epidemiology awarded to Kelly W. Burak in November 2005 from the University of Calgary for a thesis entitled "Does the MELD Score Predict Mortality before and after Liver Transplantation at the University of Alberta?" available online at http://dspace.ucalgary.ca/handle/1880/44826. The authors would like to thank Drs. Eric Yoshida (BC Transplant, Vancouver, BC), Les Lilly (University Health Network Multi-Organ Transplant Program, Toronto, ON), Paul Marotta (London Health Sciences Centre Multi-Organ Transplant Program, London, ON), Peter Ghali (McGill University, Montreal, PQ), Marc Bilodeau (Centre Hospitalier de l'Universite de Montréal, Montreal, PQ), and Kevork Peltekian (Multi-Organ Transplant Program, Halifax, NS) for completing the survey on current use of MELD in Canada.

\section{References}

[1] R. P. Myers, M. Krajden, M. Bilodeau et al., "Burden of disease and cost of chronic hepatitis C virus infection in Canada," Canadian Journal of Gastroenterology and Hepatology, vol. 28, no. 5, pp. 243-250, 2014.

[2] M. R. Lucey, K. A. Brown, G. T. Everson et al., "Minimal criteria for placement of adults on the liver transplant waiting list: a report of a national conference organized by the American Society of Transplant Physicians and the American Association for the Study of Liver Diseases," Liver Transplantation and Surgery, vol. 3, no. 6, pp. 628-637, 1997.

[3] R. B. Freeman Jr., R. H. Wiesner, A. Harper et al., "The new liver allocation system: moving toward evidence-based transplantation policy," Liver Transplantation, vol. 8, no. 9, pp. 851-858, 2002.

[4] M. Malinchoc, P. S. Kamath, F. D. Gordon, C. J. Peine, J. Rank, and P. C. J. Ter Borg, "A model to predict poor survival in 
patients undergoing transjugular intrahepatic portosystemic shunts," Hepatology, vol. 31, no. 4, pp. 864-871, 2000.

[5] P. S. Kamath, R. H. Wiesner, M. Malinchoc et al., "A model to predict survival in patients with end-stage liver disease," Hepatology, vol. 33, no. 2, pp. 464-470, 2001.

[6] F. Botta, E. Giannini, P. Romagnoli et al., "MELD scoring system is useful for predicting prognosis in patients with liver cirrhosis and is correlated with residual liver function: a European study," Gut, vol. 52, no. 1, pp. 134-139, 2003.

[7] R. H. Wiesner, S. V. McDiarmid, P. S. Kamath et al., "MELD and PELD: application of survival models to liver allocation," Liver Transplantation, vol. 7, no. 7, pp. 567-580, 2001.

[8] R. Wiesner, E. Edwards, R. Freeman et al., "Model for endstage liver disease (MELD) and allocation of donor livers," Gastroenterology, vol. 124, no. 1, pp. 91-96, 2003.

[9] R. B. Freeman Jr., "MELD/PELD: one year later," Transplantation Proceedings, vol. 35, no. 7, pp. 2425-2427, 2003.

[10] K. M. Olthoff, R. S. Brown Jr., F. L. Delmonico et al., "Summary report of a national conference: evolving concepts in liver allocation in the MELD and PELD era," Liver Transplantation, vol. 10, supplement 2, pp. A6-A22, 2004.

[11] J. A. Hanley and B. J. McNeil, "The meaning and use of the area under a receiver operating characteristic (ROC) curve," Radiology, vol. 143, no. 1, pp. 29-36, 1982.

[12] W. K. Kremers, M. van Ijperen, W. R. Kim et al., "MELD score as a predictor of pretransplant and posttransplant survival in OPTN/UNOS status 1 patients," Hepatology, vol. 39, no. 3, pp. 764-769, 2004.

[13] W. R. Kim, S. W. Biggins, W. K. Kremers et al., "Hyponatremia and mortality among patients on the liver-transplant waiting list," New England Journal of Medicine, vol. 359, no. 10, pp. 10181026, 2008.

[14] M. D. Leise, W. R. Kim, W. K. Kremers, J. J. Larson, J. T. Benson, and T. M. Therneau, "A revised model for end-stage liver disease optimizes prediction of mortality among patients awaiting liver transplantation," Gastroenterology, vol.140, no. 7, pp. 1952-1960, 2011.

[15] C. Toso, S. Asthana, D. L. Bigam, A. M. J. Shapiro, and N. M. Kneteman, "Reassessing selection criteria prior to liver transplantation for hepatocellular carcinoma utilizing the scientific registry of transplant recipients database," Hepatology, vol. 49, no. 3, pp. 832-838, 2009.

[16] K. W. Burak and N. M. Kneteman, "An evidence-based multidisciplinary approach to the management of hepatocellular carcinoma (HCC): the Alberta HCC algorithm," Canadian Journal of Gastroenterology, vol. 24, no. 11, pp. 643-650, 2010.

[17] M. Bhat, P. Ghali, A. Roy et al., "A novel MELD exception point system for hepatocellular carcinoma promotes equitable liver allocation," Hepatology, vol. 60, no. 1, supplement, article 199A, 2014. 


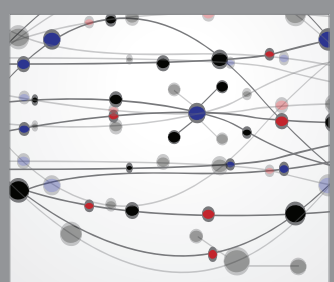

The Scientific World Journal
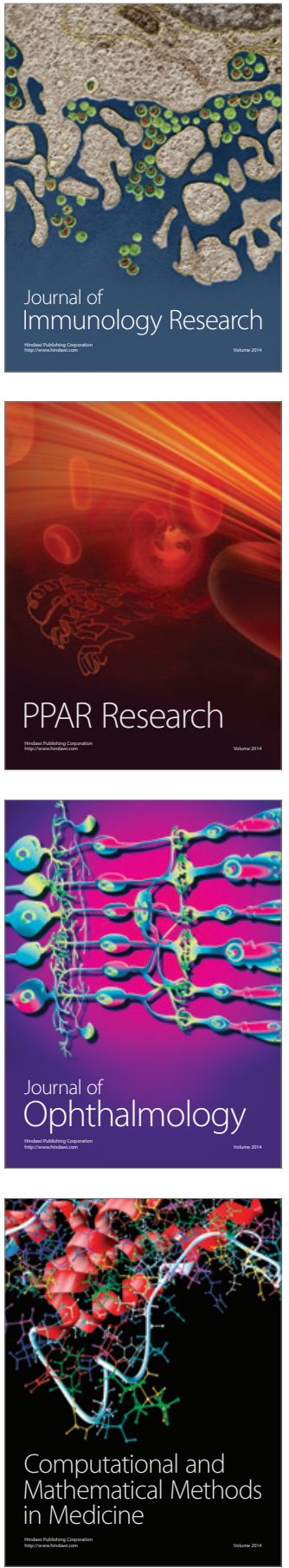

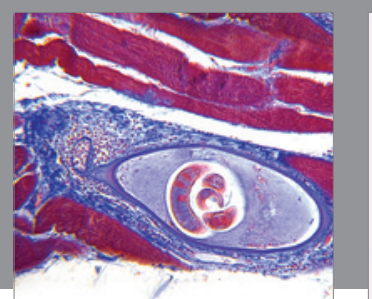

Gastroenterology Research and Practice

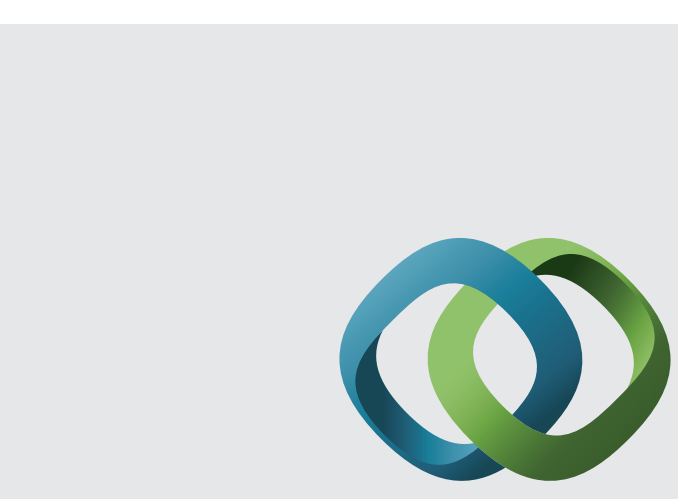

\section{Hindawi}

Submit your manuscripts at

http://www.hindawi.com
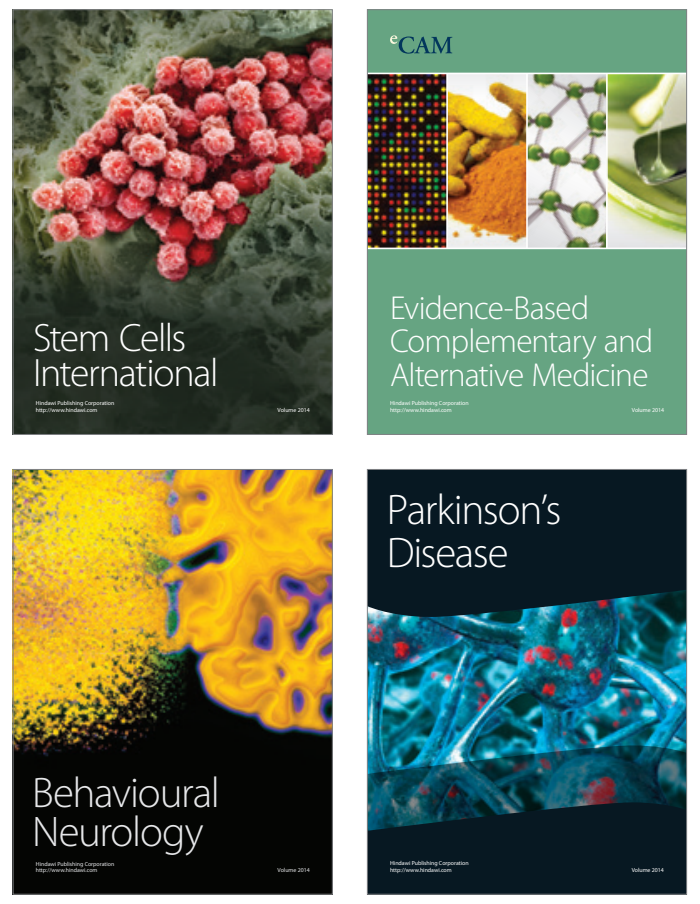
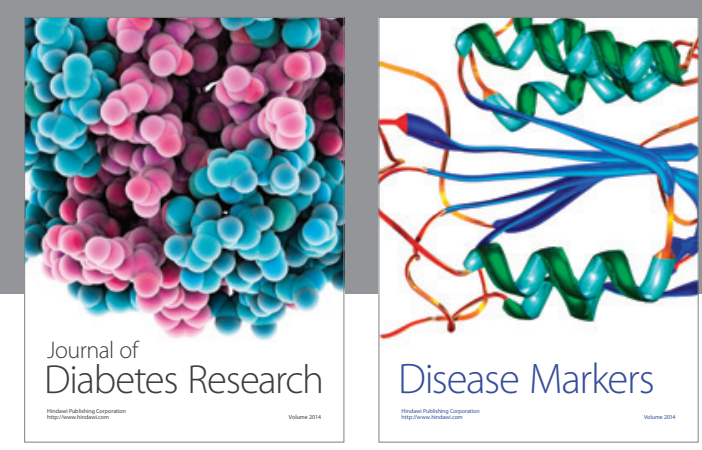

Disease Markers
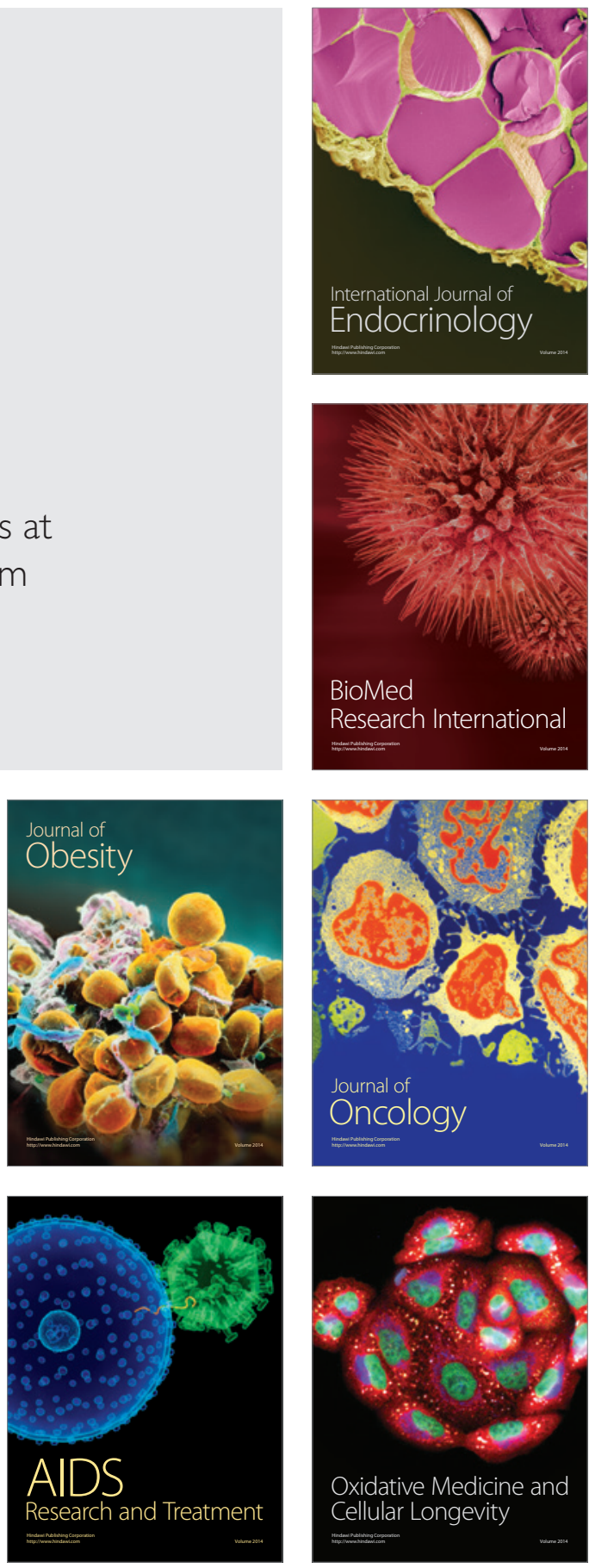